Oikos

December 2020, Volume 129, Issue 12, Pages 1856-1866

https://doi.org/10.1111/oik.07501

https://archimer.ifremer.fr/doc/00643/75487/

\title{
Tropical cyclones and island area shape species abundance distributions of local tree communities
}

Ibanez Thomas 1, 2, 17, *, Keppel Gunnar ${ }^{3,4}$, Baider Cleudia ${ }^{5}$, Birkinshaw Chris ${ }^{6}$, Vincent Florens Fb 7 , Laidlaw Melinda ${ }^{8}$, Menkes Christophe ${ }^{9}$, Parthasarathy Narayanaswamy ${ }^{10}$, Rajkumar Muthu 10, 11 , Ratovoson Fidy ${ }^{12}$, Rasingam Ladan ${ }^{13}$, Reza Ludovic ${ }^{12}$, Aiba Shin-Ichiro ${ }^{14}$, Webb Edward L ${ }^{15}$, Zang Rungo ${ }^{16}$, Birnbaum Philippe ${ }^{1,2}$

1 Institut Agronomique néo-Calédonien (IAC), Equipe Sol \& Végétation (SolVeg), BPA5, 98800

Nouméa, New Caledonia

2 AMAP, CIRAD, CNRS, INRA, IRD, Univ Montpellier, Montpellier, France

${ }^{3}$ School of Natural and Built Environments and Future Industries Institute, University of South Australia,

Mawson Lakes Campus, GPO Box 2471, Adelaide, South Australia 5001, Australia

${ }^{4}$ Biodiversity, Macroecology \& Biogeography, University of Goettingen, Büsgenweg 1, 37077 Göttingen, Germany

${ }^{5}$ The Mauritius Herbarium, Agricultural Services, Ministry of Agro-Industry and Food Security, 80835,

Réduit, Mauritius

${ }^{6}$ Missouri Botanical Garden - Programme Madagascar, Lot VP 31 Ankadibevava Anjohy, BP 3391,

Antananarivo 101, Madagascar

7 Tropical Island Biodiversity, Ecology and Conservation Pole of Research, Department of Biosciences

and Ocean Studies, University of Mauritius, Réduit, Mauritius

${ }^{8}$ Queensland Herbarium, Department of Environment and Science, Toowong, 4066, Australia

9 IRD, ENTROPIE (UMR 9220), BP A5, 98848 Nouméa Cedex, New Caledonia

10 Department of Ecology and Environmental Sciences, Pondicherry University, Puducherry, 605014, India

11 Tropical Forest Research Institute, Jabalpur, 482021, Madhya Pradesh, India

12 Missouri Botanical Garden, Madagascar Research and Conservation Program, BP 3391,

Antananarivo 101, Madagascar

${ }^{13}$ Botanical Survey of India, Deccan Regional Center, Hyderabad, 500048 Telangana, India

${ }^{14}$ Graduate School of Science and Engineering, Kagoshima University, 890-0065 Kagoshima, Japan

${ }^{15}$ Department of Biological Sciences, National University of Singapore, 14 Science Drive 4, 117543,

Singapore

${ }^{16}$ Key laboratory of biodiversity conservation,the state forestry and grassland administration, Institute of Forest Ecology, Environment, and Protection, Chinese Academy of Forestry, Beijing, 100091 China

17 Department of Biology, University of Hawai'i at Hilo, Hawai'i, USA

*Corresponding author : Thomas Ibanez, email address : thomas.paul.ibanez@gmail.com

\begin{abstract}
:
Species abundance distributions (SADs) characterise the distribution of individuals among species. SADs have rarely been explored on islands and the ecological processes shaping SADs are still not fully understood. Notably, the relative importance of disturbance regime in shaping plant SADs remains poorly known. We investigate the relative importance of disturbance regime and island geography on the shape
\end{abstract}


of SADs. We computed SADs for local tree communities in 1-ha forest plots on 20 tropical islands in the Indo-Pacific region. We used generalized linear models to analyse how the shape parameter of the gambin SAD model was related to the number of trees and the number of species. Regression analyses were also used to investigate how the shape of SADs, the number of trees, and the number of species were related to cyclone disturbance (power dissipation index) and geography (island area and isolation), with direct and indirect (i.e., through the number of trees and species) effects assessed using variance partitioning. Cyclone disturbance was the best predictor of the shape of SADs, with higher power dissipation index producing more lognormal-like distributions. This effect was mostly due to cyclones increasing the number of trees and decreasing the number of species. Island area affected the shape of SADs through its effect on the number of species, and larger islands were associated with higher species richness and more logseries-like distributions. The effect of cyclones was stronger on smaller islands. Our results illustrate that disturbances can affect SADs in complex ways; directly and indirectly by impacting the number of species and individuals in communities, and these effects may be moderated by islandspecific characteristics, such as island area or isolation. Our results therefore suggest that multiple, interacting processes shape SADs and that studying SADs has the potential to contribute important new insights to the field of island biogeography.

Keywords : area, disturbance, hurricane, isolation, rain forest, species abundance distribution (SAD), species-area relationship (SAR), species diversity, theory of island biogeography, tropical cyclone, typhoon 


\section{Introduction}

The species abundance distribution (SAD) illustrates an important aspect of biodiversity because it accounts for both the number of species and their abundances in a community (McGill et al., 2007). Most species within a community are often rare and represented by a single or few individuals, while only a few species are abundant (Chisholm \& Pacala, 2010). This pattern is particularly pronounced in species-rich communities such as tree communities in tropical forests (e.g., Volkov, Banavar, Hubbell \& Maritan, 2007). However, documented shapes of SADs vary considerably and studying these variations can provide important insights into the processes driving the composition and diversity of communities (see reviews by Matthews et al., 2014; McGill et al., 2007; Ulrich, Ollik \& Ugland, 2010). Yet, the ecological processes shaping SADs, such as the relative importance of disturbances, remain poorly understood.

Islands can provide natural experiments that help to better understand ecological and evolutionary processes (e.g., MacArthur \& Wilson, 1967; Vitousek, 2002). Speciesarea relationships (SARs) and related approaches that may include other predictors (e.g., Whittaker, Triantis \& Ladle, 2008) have been the main approach used to understand drivers of community assembly on islands (e.g., MacArthur \& Wilson, 1967; Triantis, Mylonas, Lika \& Vardinoyannis, 2003). Because SADs also account for the abundance of species, they have great potential to improve our understanding of community assembly on islands but have hardly been used in that context (Borges et al., 2018; Fattorini, Rigal, Cardoso \& Borges, 2016). Studying the variation of SADs in island systems should provide new insights on the processes shaping SADs and island biodiversity (Matthews, Borges, de Azevedo \& Whittaker, 2017; Patiño et al., 2017).

Because SADs are derived from samples of communities and take into account both the number of species and their abundance in the community, the factors shaping 
SADs are complex and interacting. For island communities, SADs can be affected by direct effects that act on a community-level, and indirect effects that influence the number of species and individuals that could be expected to be found in a community due to characteristics of the island that occurs on. The shape of a SAD is strongly constrained by the number of species and individuals forming a community (Locey \& White, 2013), therfore, it should be influenced by the geography of an island (e.g., its size and isolation). On islands, the number of species increases with increasing island size and decreasing island isolation at both the island (MacArthur \& Wilson, 1967) and the local (Ibanez, Keppel, et al. 2018; Keppel et al, 2010) scales. Furthermore, the proportion of locally rare species tends to increase with species richness (Locey \& White, 2013). Local communities on species-rich islands (larger or less isolated) should therefore exhibit more logseries-like SADs (for which most species are locally rare and few species are very abundant), while communities on species-poor islands (smaller or more isolated) should exhibit more lognormal-like distributions.

It has long been suggested that the shape of SADs should be affected by stresses and disturbances (e.g., Gray \& Mirza, 1979; Matthews \& Whittaker, 2015). So far most studies exploring the relationship between the shape of SADs and different levels of stress or disturbance have focused on animal communities and no real consensus has emerged on the nature and strength of this relationship (e.g., Gray \& Mirza, 1979; Hamer, Hill, Lace \& Langan, 1997; Ugland \& Gray, 1982). Tropical islands are suitable for investigating the effects of disturbance, as they are subjected to different cyclone disturbance regimes. For instance, islands located close to the equator never experience cyclones, while tropical cyclones are often frequent and intense on islands between 1525 degrees North or South. 
Frequent and intense tropical cyclones are known to increase tree density in tropical forests (Ibanez et al., 2019; Keppel, Buckley \& Possingham 2010; Quigley \& Platt, 2003) and this should impact SADs, which are affected by sample size (Chisholm, 2007; McGill, 2003). The proportion of locally rare species within a sample tends to decrease with more individuals and/or greater area being sampled (Chisholm, 2007; Locey \& White, 2013; McGill, 2003; Preston, 1948). For a given sample area (e.g., plots 1 ha in size), communities with higher densities of individuals should therefore exhibit more lognormal-like distributions (most species have intermediate abundances with few species being either rare or very abundant).

Cyclones can also cause selective mortality and/or establishment of species. For instance, early successional species which usually have light wood are more likely to experience severe damages than species with denser wood, but are also more likely to establish after canopy opening by tropical cyclone (e.g., Curran, Brown et al., 2008; Curran, Gersbach, Edwards \& Krockenberger, 2008; Webb et al., 2014). In the longterm, frequent cyclones are believed to increase the proportion of early successional species at the expense of species that are habitat specialists (Webb, Seamon, \& Fa'aumu 2011). These changes in species composition should affect the shape of SADs, as habitat specialists tend to be locally rare (Umaña et al., 2017). Together, the direct effects on the composition of tree communities, and the indirect effects on the number of trees, should lead to more lognormal-like SADs but direct evidence of cyclone impacts on tree SADs does not exist.

Plant communities tend to exhibit logseries-like SADs, but there is considerable variation (Ulrich et al., 2010). SADs of forest tree communities tend to be more logseries-like at lower latitudes and elevations and more lognormal-like at higher latitudes and elevations (Arellano et al., 2017; Ulrich, Kusumoto, Shiono \& Kubota, 
2016). In drylands (mean annual precipitation $<1500 \mathrm{~mm}$ ) lognormal-like SADs have been shown to be associated with lower annual precipitation, higher aridity, high soil carbon content and higher variability of climate variables and soil nitrate (Ulrich, Soliveres, Thomas, Dougill \& Maestre, 2016). More recently, Xu, Wang, Li, Wang \& Han (2019) found that in a desert steppe, lognormal-like SADs were associated with high annual precipitation and that climate had a greater effect than disturbance by grazers on the shape of SADs. Therefore, climate can affect the shape of a SAD, and must be accounted for when evaluating the relative importance of other factors such as disturbances.

Here we evaluate the relative importance of island geography (area and isolation) and cyclone disturbance regime on SADs in local, plot-scale, communities. We analyse how a measure that combines cyclone frequency and intensity affect the shape of tree SADs in humid tropical forest using a large dataset covering 20 islands located in the Indo-Pacific region. We hypothesized that the size and isolation of islands would affect SADs through their effect on the island species pool (Ibanez, Keppel, et al., 2018). Due to lower species richness, communities located on small and isolated islands should exhibit lower proportions of locally rare species and more lognormal-like SADs than communities located on larger and less isolated islands. Cyclone disturbance regime should affect SADs by changing both the total number of individuals present in a community and the species composition. Due to higher tree density and potentially less habitat specialist species, communities experiencing more frequent or intense tropical cyclones should exhibit more lognormal-like SADs than communities less affected by cyclones.

\section{Material and methods}

'This article is protected by copyright. All rights reserved.' 


\section{Study plots}

We obtained tree species abundance data, i.e., the number of individuals for each tree species within a community, for 51 1-ha plots in humid tropical forests on 20 islands (13 archipelagos) in the Indo-Pacific region (Figure 1 and Table 1). We only considered plots without any evidence of recent natural or anthropogenic disturbances (e.g., secondary forest plots, as defined by the author of source data, were removed). In each plot, all trees with a stem diameter $\geq 10 \mathrm{~cm}$ at c. $1.3 \mathrm{~m}$ above the base (DBH, diameter at breast height) were identified. All plots were located in lowland forests on islands larger than $1 \mathrm{~km}^{2}$. Nomenclature was verified and corrected using the Taxonomic Name Resolution Service v4.0 (http://tnrs.iplantcollaborative.org/). For taxa without resolution we referred to The Plant List (http://www.theplantlist.org/).

\section{Explanatory variables}

We analysed how the shape of SADs varied among islands as a function of island area (Area) and isolation (distance to the nearest continent, Dist), and cyclone disturbance regime. Differences in climate between different tropical lowland humid forests only had minor effects on SADs (Supporting Material S1). Island area (Area) and isolation (Dist) were extracted from the Island Directory (http://islands.unep.ch). The effects of tropical cyclones were assessed using power dissipation index (PDI), a proxy of the energy released by cyclones (Emanuel, 2005). This index was chosen rather than frequency (or return interval) as it integrates both the frequency and intensity of tropical cyclones and performs well as an indicator of the overall cyclone disturbance regime (Ibanez et al. 2019). The PDI was computed following Vincent et al. (2011) and Menkes et al. (2016) over the 1981-2016 period from the IBTrACs database (https://www.ncdc.noaa.gov/ibtracs/, see Knapp, Kruk, Levinson, Diamond \& 
Neumann, 2010). The IBTrACs database provides information on the position, maximum sustained wind speed and translation speed of each inventoried cyclone at 6-h intervals. We used this data to calculate the average frequency of tropical cyclones for each grid cell with a spatial resolution of $1^{\circ}$ latitude $\times 1^{\circ}$ longitude $\left(\approx 12345 \mathrm{~km}^{2}\right.$ at the equator). Only events reaching maximum sustained wind speed $>17 \mathrm{~m} \cdot \mathrm{s}^{-1}$ at some point along the cyclone track were considered, i.e. tropical storms and category one to five tropical cyclones according to the Saffir-Simpson Hurricane Scale. Explanatory variables were not strongly correlated (Spearman's Rho $<0.70$, see Table S1).

\section{Species abundance distribution}

The effect of different variables on SADs may be assessed by fitting SAD models to the observed distributions and analysing how the parameters (e.g., Fattorini et al., 2016; Matthews et al., 2017; Ulrich, Kusumoto et al., 2016) or performance (e.g., Ulrich et al., 2010; Ulrich, Soliveres et al., 2016) of the models respond to different explanatory variables. Several such models have been developed (e.g., McGill et al., 2007). Here we used the gambin model (Ugland et al., 2007) because it provides good fits to both logseries- and lognormal-like distributions and can be summarized by a single and easy to interpret parameter, alpha gambin ( $\alpha$ ) (Matthews et al., 2014). A low $\alpha$ characterizes a community with a high frequency of species with low abundances (more logserieslike distribution), while a higher a characterises a community with a more normal distribution on a log scale (more lognormal-like distribution, see Figure 2). It has been suggested that the $\alpha$ parameter may help to better understand how disturbances shape the structure of communities (Matthews \& Whittaker, 2015). 
The $\alpha$ parameter was estimated for each plot using the gambin $\mathrm{R}$ package (Matthews et al., 2014). Although the mathematical formula for estimating $\alpha$ does not have parameters for the number of individuals and species (see Ugland et al., 2007), the possible shapes of SADs are highly dependent on the number of individuals and species (Locey \& White, 2013; Matthews et al., 2014). Given that the number of trees per plot varied about 3-fold in our data set, $\alpha$ was also estimated controlling for different sampling sizes $\left(\alpha_{\text {stand }}\right)$. Standardization was done by randomly subsampling 400 trees per plot before fitting gambin models, and repeating the process 100 times for each plot before estimating $\alpha_{\text {stand }}$ as the mean value of $\alpha_{\mathrm{i}}$ from all iterations. We then correlated the number of trees and the number of tree species with $\alpha$ and $\alpha_{\text {stand }}$ for each plot.

\section{Analyses}

We first used generalized linear models to analyse (i) how variation in $\alpha$ and $\alpha_{\text {stand }}$ were associated with the number of trees and the number of species, (ii) how variation in $\alpha$, $\alpha_{\text {stand, }}$ the number of trees, and the number of species were associated with island geography (log-transformed Area and Dist) and cyclone disturbance regime (PDI), and (iii) the direct and indirect effects (through their effects on the number of trees and species) of Area, Dist, PDI, on $\alpha$ and $\alpha_{\text {stand }}$. For $\alpha$ and $\alpha_{\text {stand }}$ (skewed continuous variables) we used a Gamma distribution while for the number of trees and the number of species (discrete variables) we used a Poisson distribution. In both cases a log linkfunction was used. Secondly, we used the MuMIn R package and the dredge function to generate and compare different sets of models representing all possible combinations and subsets of fixed effects (PDI, Area, Dist), and their two-way interaction terms in explaining variation in $\alpha, \alpha_{\text {stand }}$, the number of trees, and the number of species. Models were considered to belong to the set of best models, if their corrected Akaike 
Information Criterion $\left(\mathrm{AIC}_{\mathrm{c}}\right)$ values were within 2 units $\left(\Delta \mathrm{AIC} \mathrm{C}_{\mathrm{c}} \leq 2\right)$ of that of the model with the lowest value (see 2003; Bunnefeld \& Phillimore, 2012).

To account for variation within islands and because sampling intensity differed between islands (10 islands were represented by a single plot), we randomly selected 1 plot for each island with more than 1 plot before fitting and selecting the best models. The parameters of the best models were averaged using the model.avg function. Averaged parameters were computed by only averaging over the models where the variables were selected within the best models. This procedure was repeated 500 times and the effects of each variable was finally estimated as the average of the 500 averaged parameters. We also computed the number of times variables were selected within the best models among the 500 iterations as an indicator of the robustness of the effects of variables.

Cyclone disturbance regime (PDI) and island geography (Area and Dist) can directly affect the shape of SADs but also indirectly through their effects on the number of trees and species. We quantified the direct and indirect effects of the cyclone disturbance regime and island biogeography on $\alpha$ and $\alpha_{\text {stand }}$ using the variance partitioning varPart function from the modEvA R package. Variance partitioning was conduced using pseudo- $\mathrm{R}^{2}$ (the proportion of variance explained by the models with different combination of factors) as input.

\section{Results}

Correlations between $\alpha, \alpha_{\text {stand, }}$, the number of trees, and the number of species

The shape parameter of SADs, $\alpha$, varied tenfold across the studied plots, ranging from 0.60 for a plot located on Normanby island (D'Entrecasteaux archipelago) to 7.44 for a 
plot located on Tutuila island (Samoan archipelago). Lower $\alpha$ values (i.e., more logseries-like SADs) were associated with lower numbers of trees (i.e., lower tree densities) and higher numbers of tree species (Figure 3 A-B). The number of species was not significantly correlated to the number of trees (Spearman's Rho=-0.01, $\mathrm{p}=$ 0.960 ) and had a weaker effect on $\alpha$ than on the number of trees (lower $\mathrm{R}^{2}$, Figure 3 ). Once standardized for different tree density, the standardized shape parameter, $\alpha_{\text {stand }}$, was not affected by the number of trees but was still negatively associated to the number of species (Figure $3 \mathrm{C}-\mathrm{D}$ ).

Factors affecting $\alpha, \alpha_{\text {stand, }}$, the number of trees, and the number of species

The main factors explaining the observed variation strongly differed for $\alpha, \alpha_{\text {stand }}$, the number of trees, and the number of species (Figures 4-5). Cyclone regime (PDI) was the only factor that significantly affected all $\alpha, \alpha_{\text {stand, }}$, the number of trees, and the number of species. Variation in $\alpha$ was mostly associated with variation in PDI, with higher $\alpha$ values being associated with higher PDI (Figure 5A). PDI has also a significant positive effect on $\alpha_{\text {stand }}$ (Figure 5B) but this effect tended to decrease (negative interaction terms) with increasing island area (Area) and isolation (Dist). Island area has a negative effect on $\alpha$ and $\alpha_{\text {stand }}$ that decreased with island isolation (negative interaction term between Area and Dist). PDI has a significant negative effect on the number of species (Figure 5G) but this effect was weaker (lower standardized coefficient) than the positive effect of island area (Figure 5H). PDI and, to a lesser extent, island isolation (Dist) had significant positive effects on the number of trees (Figure 5J-L).

Variation partitioning 
Together, PDI, the number of trees, and the number of species explained on average $>60 \%$ of the variance in $\alpha$ (Figure 6A). PDI and its interaction with the number of trees and the number of species was the variable that explained the most variance in $\alpha(48 \%$, i.e., $76 \%$ of the total explained variance). The direct effect of PDI was however relatively low representing only $12 \%$ of the explained variance in $\alpha$. The interaction between PDI and the number of trees had a particularly strong effect on $\alpha$, explaining $15 \%$ of its variance. Island geography (i.e., Area, Dist, and their interaction) similarly had a low direct effect on $\alpha$ (explaining on average only $7 \%$ of its variance). In contrast with PDI, the indirect effect of island geography was mainly through its interaction with the number of species (Figure 6B). However, the indirect effects of island geography explained less the variation in $\alpha$ than did those of PDI (26\% and 36\%, respectively). When standardized for differences in tree density, the variance in the shape parameter explained by the direct effects of PDI and island geography both more than doubled (Figure 6C-D). The variance in $\alpha_{\text {stand }}$ explained by the number of trees and their interactions overall decreased while the variance explained by the number of species and its interactions increased.

\section{Discussion}

Our results show that disturbances can considerably shape species abundance distributions (SADs). In our case, higher power dissipation indices (PDI) due to more frequent and/or intense cyclones promoted more lognormal-like SADs, i.e., it reduced the number of locally rare species and increased the proportion of species with medium abundance. This effect was mostly facilitated by increasing cyclone disturbance increasing the number of individuals and decreasing the number of species within the studied tree communities. Island geography also affected SAD shape, predominantly by 
affecting the number of species within the studied communities. Communities, sampled using plots, exhibited higher species richness and more logseries-like distributions, i.e., a higher proportion of locally rare species and lower proportion of abundant species, when located on larger and/or less isolated islands. Our results also suggest that disturbance by cyclones may have more pronounced effects on the SADs of smaller and/or more isolated islands.

\section{Tropical cyclones shape SADs}

Energy released by tropical cyclones (i.e., the PDI) was the variable that had the most consistent effect on the shape parameter $\alpha$ of SADs, having a strong positive effect on $\alpha$. Therefore, frequent and/or intense cyclones appeared to drive SADs toward more lognormal-like distributions, by decreasing the proportion of locally rare species and increasing the proportion of intermediately abundant species. Tropical cyclones mainly shaped SADs through their positive effect on the number of trees as has been shown in other studies (Ibanez et al., 2019; Keppel, Buckley \& Possingham 2010; Quigley \& Platt, 2003), and their negative effect on the number of species.

More frequent and/or intense cyclones may decrease the number of species by creating environmental conditions favouring disturbance-adapted (light-demanding) species over habitat specialists (shade-tolerant). Although light-demanding, fastgrowing (low wood density) disturbance-adapted species experience higher morality due to tropical cyclones (e.g., Curran, Brown et al., 2008; Webb et al., 2014), canopy openings favour their recruitment over shade-tolerant, slow-growing (high wood density) habitat specialist species (e.g., Comita et al., 2009; Curran, Gersbach, Edwards \& Krockenberger, 2008; Webb et al., 2011). Therefore, high cyclone frequency and/or intensity should not only drive SADs towards more lognormal-like distributions but also 
toward lower functional diversity and species richness by favouring disturbance-adapted species (Comita et al., 2009; Hogan et al., 2018; Webb et al., 2011).

It has been suggested that smaller islands are particularly prone to disturbances (Whittaker, 1995). Our results support that cyclones could have stronger impacts on SADs on smaller or more isolated islands. The lower impact on larger islands could be related to such islands generally being higher and topographically more complex (Borregaard, Matthews \& Whittaker, 2015), offering more shelter against cyclonic winds. It has indeed been observed that topographic complexity can create patches of vegetation that are less impacted by cyclones (e.g., Staben \& Evans 2008). The shape of SADs should also be less affected by cyclone disturbances on less isolated islands because local extinction of habitat specialist species would be more likely to be compensated by colonization events from the mainland.

Hence, disturbance-adapted generalists should be most favoured on smaller and/or more isolated islands with high cyclonic disturbance. However, further studies are required to confirm that the changes in SADs with increasing disturbances by cyclones are indeed related to the loss of locally rare habitat specialists from sampled communities, the increased dominance of disturbance-adapted generalists, and functional homogenization. Functional traits likely to be affected by cyclone disturbance, such as wood density, could help further investigating functional homogenisation and the relative importance of cyclones versus geographical factors in shaping the structure and composition of communities (Keppel et al., 2018; Ottaviani et al., 2020). Furthermore, the effect of cyclone disturbance on the shape of SADs in our study may also be related to the effects of biogeographical factors that have not been taken into account in our analysis (e.g., islands belonging to different biogeographical areas). 


\section{Island geography and SADs}

The shape of SADs was also affected by the islands' geography. Our results show that SADs tend to have a more lognormal-like distribution on small and /or isolated islands and that the effect of cyclone disturbance regime on SADs is stronger on smaller islands. Island area was also the main variable explaining variance in local, plot-scale species richness and its effect on the shape parameters of SADs was mainly due to its indirect effect on local species richness (see Ibanez, Keppel et al., 2018). This is in agreement with Borges et al. (2008) who suggested that SADs of woody plant communities sampled in forests located on more diverse islands tended to be more logseries-like (i.e., have a higher proportion of locally rare species) relative to those sampled in forest located on less diverse islands. Indeed, for a given number of individuals, higher species richness produces more logseries-like SADs, i.e., a relative high proportion of locally rare species (Locey \& White, 2013).

Therefore, SADs have the potential to considerably further our understanding of diversity patterns and community assembly on islands, helping to address some of the most fundamental questions in the field of island biogeography (Patiño et al., 2017). For example, had we only considered species richness (i.e., SARs), we would have concluded that island geography is the key driver of diversity patterns on islands. However, taking the abundances of species into account using SADs suggested that cyclone disturbance is a key driver of diversity patterns by reducing the number of locally rare species and that it is moderated by island geography - hence providing much deeper understanding of the drivers of diversity patterns and community assembly in our study system. 
Together, disturbance by tropical cyclones and island geography explained on average $65 \%$ of the variance observed in the shape of SADs between forest communities located on different islands. While some of the explained variance could be due to covariance with other variables that were not accounted for, cyclone intensity (PDI) and island geography, therefore, appear to be important determinants of the shape of SADs. The roles of cyclone disturbance and island geography should be further investigated using larger sample sizes, which would allow the usage of analytical methods that can better discern the direct and indirect effects of variables (e.g., structural equation modelling). However, this would require collecting a considerable amount of additional plot data from tropical islands.

Some of the residual variance in our analyses is likely related to differences in local environmental variation, which could not be taken into account in our analyses. While we tried to minimise the effects of local environmental variation by sampling within the same broad vegetation type (lowland tropical rainforest) and only included large plots (thereby ensuring considerable local topographic variation was included within each plot), plots will inevitably differ in fine-scale topography and microclimatic conditions. Further studies are needed to better understand the relative importance of local and regional factors in shaping island SADs.

\section{Conclusion}

Tropical cyclone disturbance exerted a strong effect on the shape of SADs of communities sampled in forest located on islands. Our study therefore provides evidence of the major role that large-scale disturbances play in shaping SADs of plant communities and the potential of SADs to further elucidate processes driving diversity patterns and community assembly on islands. Furthermore, our results highlight that 
disturbances can affect SADs in complex ways; directly and indirectly by impacting the number of species and individuals in communities, and these effects may be moderated by island-specific characteristics, such as island area or isolation. Our results therefore suggest that multiple, interacting processes shape SADs and that studying SADs has the potential to contribute important new insights to the field of island biogeography. We hypothesize that changes in SADs shape should be accompanied by changes in species and functional composition, as locally rare species are often habitat specialists (Umaña et al., 2017). Changes in cyclone regime such as increasing intensity or poleward migration (e.g., Kossin, Emanuel \& Vecchi, 2014; Knutson et al., 2010) may therefore potentially alter the composition, diversity and functioning of tropical and sub-tropical forests. Our results are consistent with cyclone disturbance producing more lognormallike SADs, potentially as a result of a decrease in locally rare habitat specialist species to the benefit of disturbance adapted generalists. However, the link between changes in SADs and changes in the species and functional composition of communities as a result of disturbances requires further investigation. 


\section{Data accessibility}

Data will be available from the Dryad Digital Repository

\section{Acknowledgements}

T. Ibanez was funded by the Agency for Economic and Environmental Development (DDEE) of the North Province of New Caledonia as well as by the National Park Service, Pacific Island Inventory \& Monitoring Network through a cooperative agreement \#P17AC00835 and. G. Keppel was partially supported by an Alexander von Humboldt fellowship. Funding by the Hermon Slade Foundation (HSF 19105) facilitated some of the analyses and writing. We thank all people who contributed to collecting plot-data. We thank Tom Matthews and one anonymous reviewer for helpful comments on the manuscript.

\section{Author's contributions}

T.I. and G.K. conceived of the idea and drafted the paper, and interpreted the results. T.I. collated and analysed the data. C.M. computed the cyclone power dissipation index map. All authors contributed to the collection of data and the writing of the paper 


\section{References}

Aiba, S. \& Kitayama, K. (1999). Structure, composition and species diversity in an altitude-substrate matrix of rain forest tree communities on Mount Kinabalu, Borneo. Plant Ecology, 140, 139-157. https://doi.org/10.1023/a:1009710618040

Arellano, G., Umaña, M.N., Macía, M.J., Loza, M.I., Fuentes, A., Cala, V., \& Jorgensen, P.M. (2017). The role of niche overlap, environmental heterogeneity, landscape roughness and productivity in shaping species abundance distributions along the Amazon-Andes gradient. Global Ecology and Biogeography, 26, 191202. https://doi.org/10.1111/geb.12531

Borges, P.A.V., Cardoso, P., Fattorini, S., Rigal, F., Matthews, T.J., Di Biase, L., ... Emerson, B.C. (2018). Community structure of woody plants on islands along a bioclimatic gradient. Frontiers of Biogeography, 10(3-4). https://doi.org/10.21425/F5FBG40295

Borregaard, M.K., Matthews, T.J., \& Whittaker, R.J. (2015). The general dynamic model: towards a unified theory of island biogeography? Global Ecology and Biogeography, n/a-n/a. https://doi.org/10.1111/geb.12348

Bunnefeld, N. \& Phillimore, A.B. (2012). Island, archipelago and taxon effects: mixed models as a means of dealing with the imperfect design of nature's experiments. Ecography, 35, 15-22. https://doi.org/10.1111/j.1600-0587.2011.07078.x

Chisholm, R.A. (2007). Sampling species abundance distributions: Resolving the veilline debate. Journal of Theoretical Biology, 247, 600-607. https://doi.org/10.1016/j.jtbi.2007.04.006

Chisholm, R.A., \& Pacala, S.W. (2010). Niche and neutral models predict asymptotically equivalent species abundance distributions in high-diversity 
ecological communities. Proceedings of the National Academy of Sciences, 107(36), 15821-15825. https://doi.org/10.1073/pnas.1009387107

Comita, L.S., Uriarte, M., Thompson, J., Jonckheere, I., Canham, C.D., \& Zimmerman, J.K. (2009). Abiotic and biotic drivers of seedling survival in a hurricane-impacted tropical forest. Journal of Ecology, 97, 1346-1359. https://doi.org/10.1111/j.1365$\underline{2745.2009 .01551 . x}$

Curran, T.J., Brown, R.L., Edwards, E., Hopkins, K., Kelley, C., McCarthy, E., ... Wolf, J. (2008). Plant functional traits explain interspecific differences in immediate cyclone damage to trees of an endangered rainforest community in north Queensland. Austral Ecology, 33, 451-461. https://doi.org/10.1111/j.14429993.2008.01900.x

Curran, T.J., Gersbach, L.N., Edwards, W., \& Krockenberger, A.K. (2008). Wood density predicts plant damage and vegetative recovery rates caused by cyclone disturbance in tropical rainforest tree species of North Queensland, Australia. Austral Ecology, 33, 442-450. https://doi.org/10.1111/j.1442-9993.2008.01899.x

Emanuel, K. (2005). Increasing destructiveness of tropical cyclones over the past 30 years. Nature, 436, 686-688.https://doi.org/10.1038/nature03906

Fattorini, S., Rigal, F., Cardoso, P., \& Borges, P.A.V. (2016). Using species abundance distribution models and diversity indices for biogeographical analyses. Acta Oecologica, 70, 21-28. https://doi.org/10.1016/j.actao.2015.11.003

Gray, J. S., \& Mirza, F. B. (1979). A possible method for the detection of pollutioninduced disturbance on marine benthic communities. Marine Pollution Bulletin, 10(5), 142 - 146. https://doi.org/10.1016/0025-326X(79)90082-1 
Hamann, A., Barbon, E.B., Curio, E., \& Madulid, D.A. (1999). A botanical inventory of a submontane tropical rainforest on Negros Island, Philippines. Biodiversity and Conservation, 8, 1017-1031. https://doi.org/10.1023/a:1008847704539

Hamer, K.C., Hill, J.K., Lace, L.A., \& Langan, A.M. (1997). Ecological and biogeographical effects of forest disturbance on tropical butterflies of Sumba, Indonesia. Journal of Biogeography, 24, 67-75. https://doi.org/10.1111/j.13652699.1997.tb00051.x

Hogan, J.A., Zimmerman, J.K., Thompson, J., Uriarte, M., Swenson, N.G., Condit, R., ... Davies, S.J. (2018). The frequency of cyclonic wind storms shapes tropical forest dynamism and functional trait dispersion. Forests, 9, 404. https://doi.org/10.3390/f9070404

Ibanez, T., Blanchard, E., Hequet, V., Keppel, G., Laidlaw, M., Pouteau, R., ... Birnbaum, P. (2018). High endemism and stem density distinguish New Caledonian from other high-diversity rainforests in the Southwest Pacific. Annals of Botany, 121, 25-35. https://doi.org/10.1093/aob/mcx107

Ibanez, T., Keppel, G., Baider, C., Birkinshaw, C., Culmsee, H., Cordell, S., ... Birnbaum, P. (2018). Regional forcing explains local species diversity and turnover on tropical islands. Global Ecology and Biogeography, 27, 474-486. https://doi.org/10.1111/geb.12712

Ibanez, T., Keppel, G., Menkes, C., Gillespie, T.W., Lengaigne, M., Mangeas, ... Birnbaum, P. (2019). Globally consistent impact of tropical cyclones on the structure of tropical and subtropical forests. Journal of Ecology, 107, 279-292. https://doi.org/10.1111/1365-2745.13039 
Kartawinata, K., Samsoedin, I., Heriyanto, M., \& Afriastini, J.J. (2004). A tree species inventory in a one-hectare plot at the Batang Gadis National Park, North Sumatra, Indonesia. Reinwardtia, 12, 145-147.

Keppel, G., Buckley, Y.M., \& Possingham, H.P. (2010). Drivers of lowland rain forest community assembly, species diversity and forest structure on islands in the tropical South Pacific. Journal of Ecology, 98, 87-95.

https://doi.org/10.1111/j.1365-2745.2009.01595.x

Keppel, G., Ottaviani, G., Harrison, S., Wardell-Johnson, G.W., Marcantonio, M., \& Mucina, L. (2018). Towards an eco-evolutionary understanding of endemism hotspots and refugia. Annals of Botany, 122(6), 927-934. https://doi.org/10.1093/aob/mcy173

Knapp, K.R., Kruk, M.C., Levinson, D.H., Diamond, H.J., \& Neumann, C.J. (2010). The International Best Track Archive for Climate Stewardship (IBTrACS). Bulletin of the American Meteorological Society, 91, 363-376. https://doi.org/10.1175/2009bams2755.1

Knutson, T.R., McBride, J.L., Chan, J., Emanuel, K., Holland, G., Landsea, C., ... Sugi, M. (2010). Tropical cyclones and climate change. Nature Geoscience, 3, 157-163.

Kossin, J.P., Emanuel, K.A., \& Vecchi, G.A. (2014). The poleward migration of the location of tropical cyclone maximum intensity. Nature, 509, 349-352. https://doi.org/10.1038/nature13278

Laidlaw, M., Kitching, R., Goodall, K., Small, A., \& Stork, N. (2007). Temporal and spatial variation in an Australian tropical rainforest. Austral Ecology, 32, 10-20. https://doi.org/10.1111/j.1442-9993.2007.01739.x 
Locey, K.J. \& White, E.P. (2013). How species richness and total abundance constrain the distribution of abundance. Ecology Letters, 16, 1177-1185. https://doi.org/10.1111/ele.12154

Lu, X., Zang, R., Ding, Y., Letcher, S.G., Long, W., \& Huang, Y. (2014). Variations and trade-offs in functional traits of tree seedlings during secondary succession in a tropical lowland rain forest. Biotropica, 46(4), $404-414$.

\section{https://doi.org/10.1111/btp.12125}

MacArthur, R.H., \& Wilson, E.O. (1967). The theory of island biogeography. Princeton, New Jersey: Princeton University Press.

Matthews, T.J., Borges, P.A.V., de Azevedo, E.B., \& Whittaker, R.J. (2017). A biogeographical perspective on species abundance distributions: recent advances and opportunities for future research. Journal of Biogeography, 44, 1705-1710. https://doi.org/10.1111/jbi.13008

Matthews, T.J., Borregaard, M.K., Ugland, K.I., Borges, P.A.V., Rigal, F., Cardoso, P., \& Whittaker, R.J. (2014). The gambin model provides a superior fit to species abundance distributions with a single free parameter: evidence, implementation and interpretation. Ecography, 37, 1002-1011. https://doi.org/10.1111/ecog.00861

Matthews, T. J., \& Whittaker, R. J. (2015). On the species abundance distribution in applied ecology and biodiversity management. Journal of Applied Ecology, 52(2), 443 - 454. https://doi.org/10.1111/1365-2664.12380

McGill, B.J. (2003). Does Mother Nature really prefer rare species or are log-leftskewed SADs a sampling artefact? Ecology Letters, 6, 766-773. https://doi.org/10.1046/j.1461-0248.2003.00491.x 
McGill, B.J., Etienne, R.S., Gray, J.S., Alonso, D., Anderson, M.J., Benecha, H.K., ... White, E.P. (2007). Species abundance distributions: moving beyond single prediction theories to integration within an ecological framework. Ecology Letters, 10, 995-1015. https://doi.org/10.1111/j.1461-0248.2007.01094.x

Menkes, C.E., Lengaigne, M., Lévy, M., Ethé, C., Bopp, L., Aumont, O., ... Jullien, S. (2016). Global impact of tropical cyclones on primary production. Global Biogeochemical Cycles, 30, 767-786. https://doi.org/10.1002/2015GB005214

Ottaviani, G., Keppel, G., Götzenberger, L., Harrison, S., Opedal, Ø.H., Conti, L., Liancourt, P., Klimeš ová, J., Silveira, F.A.O., Jiménez-Alfaro, B., Negoita, L., Doležal, J., Hájek, M., Ibanez, T., Méndez-Castro, F.E., \& Chytrý, M. (2020). Linking Plant Functional Ecology to Island Biogeography. Trends in Plant Science, $O(0)$. https://doi.org/10.1016/j.tplants.2019.12.022

Patiño, J., Whittaker, R.J., Borges, P.A.V., Fernández-Palacios, J.M., Ah-Peng, C., Araújo, M.B, ... Emerson, B.C. (2017). A roadmap for island biology: 50 fundamental questions after 50 years of The Theory of Island Biogeography. Journal of Biogeography, 44, 963-983. https://doi.org/10.1111/jbi.12986

Preston, F. W. (1948). The commones, and rarity, of species. Ecology, 29, 254 - 283. https://doi.org/10.2307/1930989

Quigley, M.F. \& Platt, W.J. (2003). Composition and structure of seasonally deciduous forests in the Americas. Ecological Monographs, 73, 87-106. https://doi.org/10.1890/0012-9615(2003)073[0087:CASOSD]2.0.CO;2 
Rajkumar, M. \& Parthasarathy, N. (2008). Tree diversity and structure of Andaman giant evergreen forests,India. Taiwania, 53, 356-358.

Rasingam, L. \& Parthasarathy, N. (2009). Tree species diversity and population structure across major forest formations and disturbance categories in Little Andaman Island, India. Tropical Ecology, 50, 89-102.

Small, A., Martin, T.G., Kitching, R.L., \& Wong, K.M. (2004). Contribution of tree species to the biodiversity of a 1 ha Old World rainforest in Brunei, Borneo. Biodiversity and Conservation, 13, 2067-2088. https://doi.org/10.1023/B:BIOC.0000040001.72686.e8

Staben, G. W., \& Evans, K. G. (2008). Estimates of tree canopy loss as a result of Cyclone Monica, in the Magela Creek catchment northern Australia. Austral Ecology, 33(4), 562 - 569. https://doi.org/10.1111/j.1442-9993.2008.01911.x

Strasberg, D. (1996). Diversity, size composition and spatial aggregation among trees on a 1-ha rain forest plot at La Réunion. Biodiversity and Conservation, 5, 825840. https://doi.org/10.1007/bf00054737

Triantis, K.A., Mylonas, M., Lika, K., \& Vardinoyannis, K. (2003). A model for the species-area-habitat relationship. Journal of Biogeography, 30(1), 19-27. https://doi.org/10.1046/j.1365-2699.2003.00805.x

Ugland, K.I. \& Gray, J.S. (1982). Lognormal distributions and the concept of community equilibrium. Oikos, 39, 171-178. https://doi.org/10.2307/3544482

Ugland, K.I., Lambshead, P.J.D., McGill, B.J., Gray, J.S., O’Dea, N., Ladle, R.J., \& Whittaker, R.J. (2007). Modelling dimensionality in species abundance distributions: description and evaluation of the Gambin model. Evolutionary Ecology Research, 9, 313-324. 
Ulrich, W., Kusumoto, B., Shiono, T., \& Kubota, Y. (2016). Climatic and geographic correlates of global forest tree species-abundance distributions and community evenness. Journal of Vegetation Science, 27, 295-305.

https://doi.org/10.1111/jvs. 12346

Ulrich, W., Ollik, M., \& Ugland, K.I. (2010). A meta-analysis of species-abundance distributions. Oikos, 119, 1149-1155. https://doi.org/10.1111/j.16000706.2009.18236.x

Ulrich, W., Soliveres, S., Thomas, A.D., Dougill, A.J., \& Maestre, F.T. (2016). Environmental correlates of species rank - abundance distributions in global drylands. Perspectives in Plant Ecology, Evolution and Systematics, 20, 56-64. https://doi.org/10.1016/j.ppees.2016.04.004

Umaña, M.N., Mi, X., Cao, M., Enquist, B.J., Hao, Z., Howe, R., ... Swenson, N.G. (2017). The role of functional uniqueness and spatial aggregation in explaining rarity in trees. Global Ecology and Biogeography, 26(7), 777-786.

https://doi.org/10.1111/geb.12583

Vincent, E.M., Lengaigne, M., Menkes, C.E., Jourdain, N.C., Marchesiello, P., \& Madec, G. (2011). Interannual variability of the South Pacific Convergence Zone and implications for tropical cyclone genesis. Climate Dynamics, 36, 1881-1896. https://doi.org/10.1007/s00382-009-0716-3

Vitousek, P.M. (2002). Oceanic islands as model systems for ecological studies. Journal of Biogeography, 29(5-6), 573-582. https://doi.org/10.1046/j.13652699.2002.00707.x 
Volkov, I., Banavar, J. R., Hubbell, S. P., \& Maritan, A. (2007). Patterns of relative species abundance in rainforests and coral reefs. Nature, 450(7166), $45-49$. https://doi.org/10.1038/nature06197

Webb, E.L. \& Fa'aumu, S. (1999). Diversity and structure of tropical rain forest of Tutuila, American Samoa: Effects of site age and substrate. Plant Ecology, 144, 257-274. https://doi.org/10.1023/A:1009862618250

Webb, E.L., Seamon, J.O., \& Fa'aumu, S. (2011). Frequent, low-amplitude disturbances drive high tree turnover rates on a remote, cyclone-prone Polynesian island. Journal of Biogeography, 38, https://doi.org/1240-1252. 10.1111/j.13652699.2011.02505.x

Webb, E.L., Van de Bult, M., Chutipong, W., \& Kabir, M.E. (2006). Composition and structure of lowland rain-forest tree communities on Ta'u, American Samoa. Pacific Science, 60, 333-354.

Webb, E.L., van de Bult, M., Fa'aumu, S., Webb, R.C., Tualaulelei, A., \& Carrasco, L.R. (2014). Factors affecting tropical tree damage and survival after catastrophic wind disturbance. Biotropica, 46, 32-41. https://doi.org/10.1111/btp.12067

Whittaker, R.J. (1995). Disturbed island ecology. Trends in Ecology \& Evolution, 10(10), 421-425. https://doi.org/10.1016/S0169-5347(00)89164-8

Whittaker, R.J., Triantis, K.A., \& Ladle, R.J. (2008). A general dynamic theory of oceanic island biogeography. Journal of Biogeography, 35, 977 - 994.

Xu, C., Wang, Z., Li, Z., Wang, L., \& Han, G. (2019). Grazing intensity and climate factors shape species abundance distribution by influencing different components of 
plant communities in a desert steppe. Ecological Research, 34(6), 730 - 742.

https://doi.org/10.1111/1440-1703.12047

'This article is protected by copyright. All rights reserved.' 


\section{Figure Legends}

Figure 1 Studied islands in the Indo-Pacific area. The background indicates the regional gradient in tropical cyclone disturbance regime, as calculated by the power dissipation index (PDI, 1 degree x 1 degree spatial resolution). Areas with higher PDI experience more frequent and/or intense tropical cyclones. Longitude and latitude are in decimal degrees.

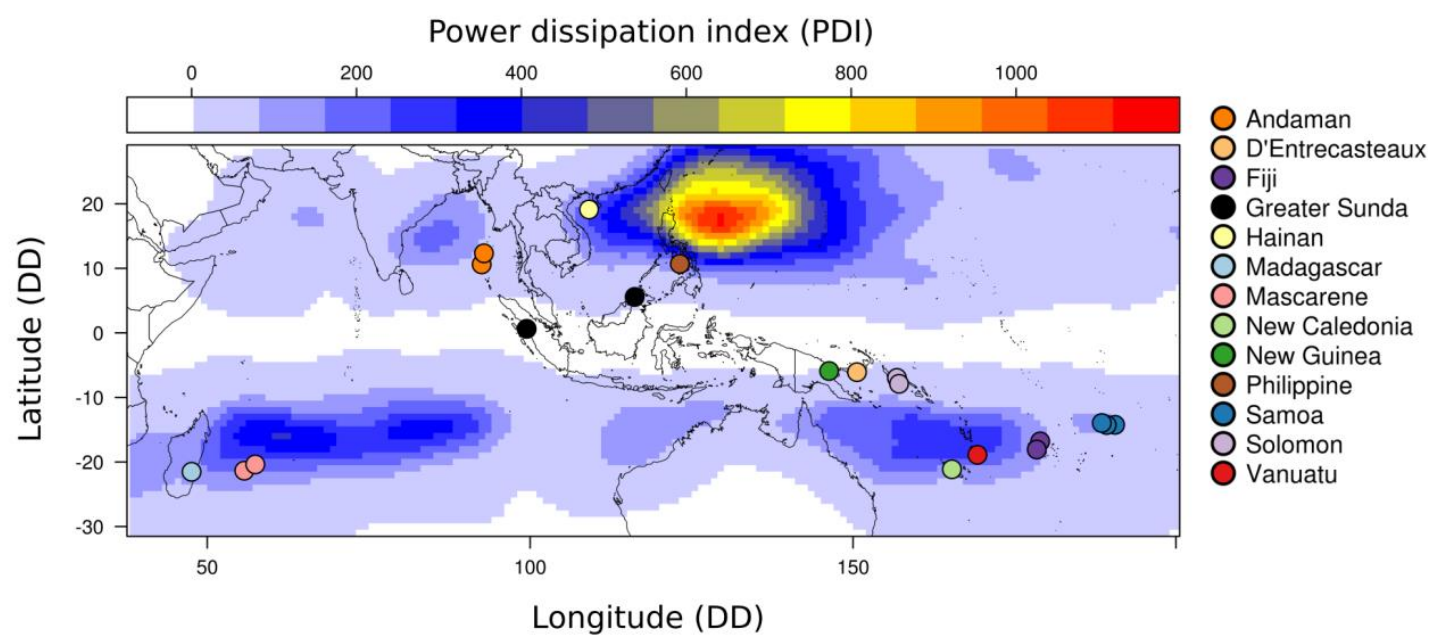

'This article is protected by copyright. All rights reserved.' 
Figure 2 Examples of SADs with increasing $\alpha$ parameters from our dataset. The abundance of species on the $\mathrm{x}$ axis were binned into octaves using $\log 2$ transformation (i.e. octave 0 represents species with 1 individual, octave 1 species with 2-3 individuals, octave 2 species with 4-7 individuals and so on). The y axis represents the relative number of species in each octave (relatively to the total number of species in the plot). Blue bars represent observed SADs and white boxes represent SADs as predicted by the alpha-gambin model. The left plot represents SAD in a 1-ha plot located in Brunei (Borneo, Small et al., 2004) with 417 trees of 187 species, the middle plot represents SAD in a 1-ha plot located on Grande Terre (New Caledonia, Ibanez, Blanchard et al., 2018) with 923 trees of 100 species and the right plot represents SAD in a 1-ha plot located on Tutuila (American Samoa, Webb \& Fa'aumu, 1999) with 938 trees of 34 species.
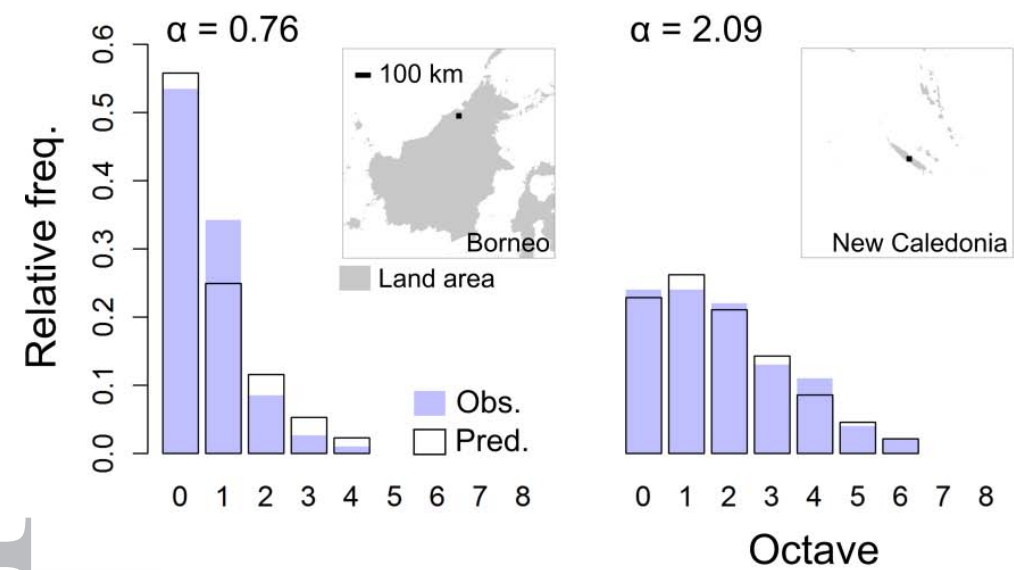

$\alpha=7.44$

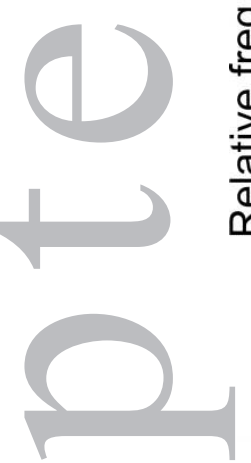

\section{Octave}


Figure 3 Linear regressions illustrating the relationships between the shape parameter of SADs (non-standardised $[\alpha]$ and standardized $\left.\left[\alpha_{\text {stand }}\right]\right)$ and the number of trees and species. Points represent the average value per island, bars the minimal and maximal values. Grey, solid trend lines represent the fits of 500 iterations of generalized linear models where a single plot was randomly selected for islands with multiple plots. Solid black trend lines represent the average fits with averaged $\mathrm{R}^{2}$ and $P$ values (distributions of $\mathrm{R}^{2}$ and $P$ values are available in Supporting Material S2). Dotted black trend lines represent the $95 \%$ confident intervals around the average trend lines. Trend lines where only showed when at least one iteration resulted in a significant relationship $(P<0.05)$.
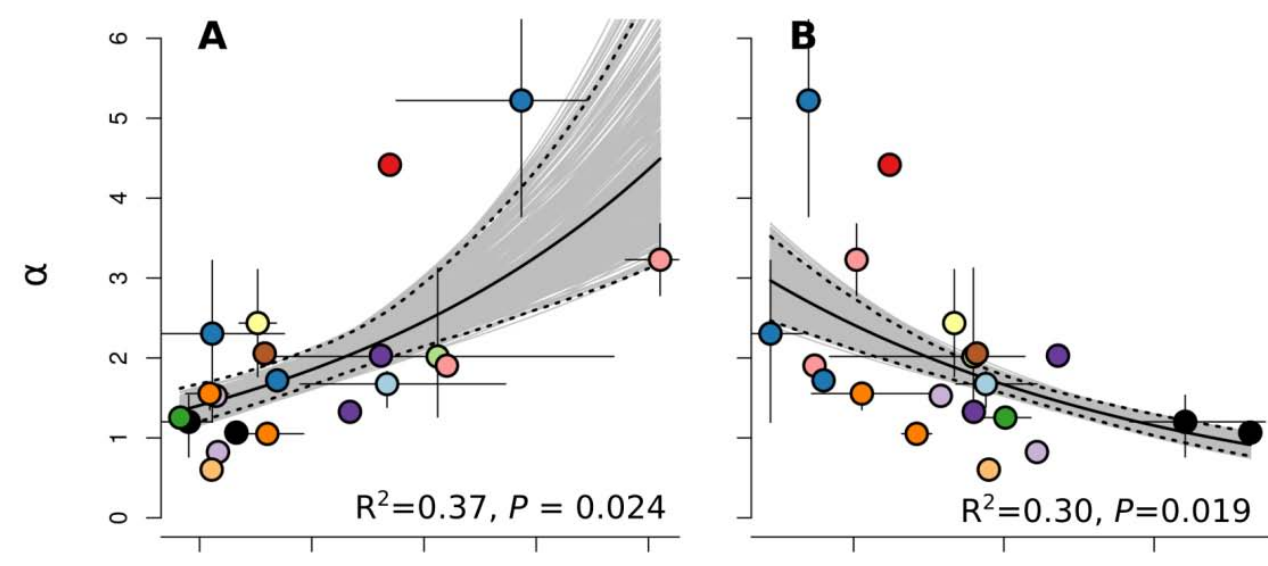

Archipelagos

Andaman

O D'Entrecasteaux

O Fij

Greater Sunda

Hainan

Madagasca

Mascarene

New Caledonia

New Guinea

Philippine

Samoa

Solomon

vanuatu

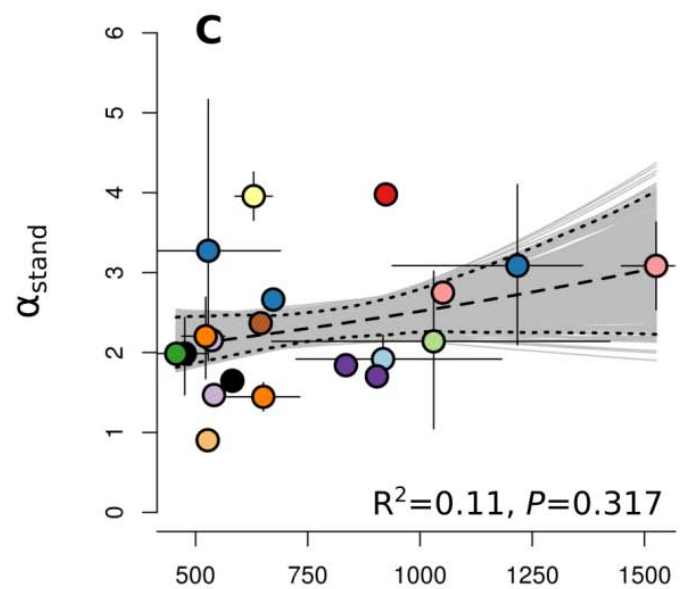

Number of trees

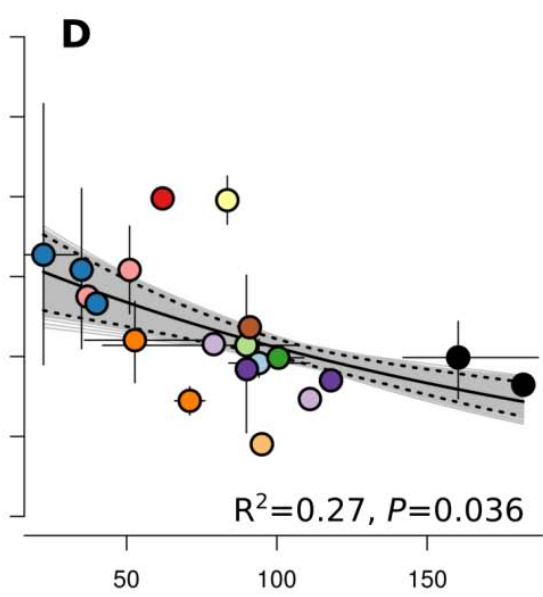

Number of species

'This article is protected by copyright. All rights reserved.' 
Figure 4 Effects of cyclone power dissipation index (PDI), island area (Area, logtransformed), island isolation (Dist., log-transformed) on the shape parameter $(\alpha)$ of SADs, the standardized shape parameter $\left(\alpha_{\text {stand }}\right)$, the number of trees $(N)$, and the number of species (R). Points represent the average coefficients and bars represent $95 \%$ confidence intervals. Values on the right represent the proportion of iterations (among 500 iterations) where the variable has been retained in best model sets.

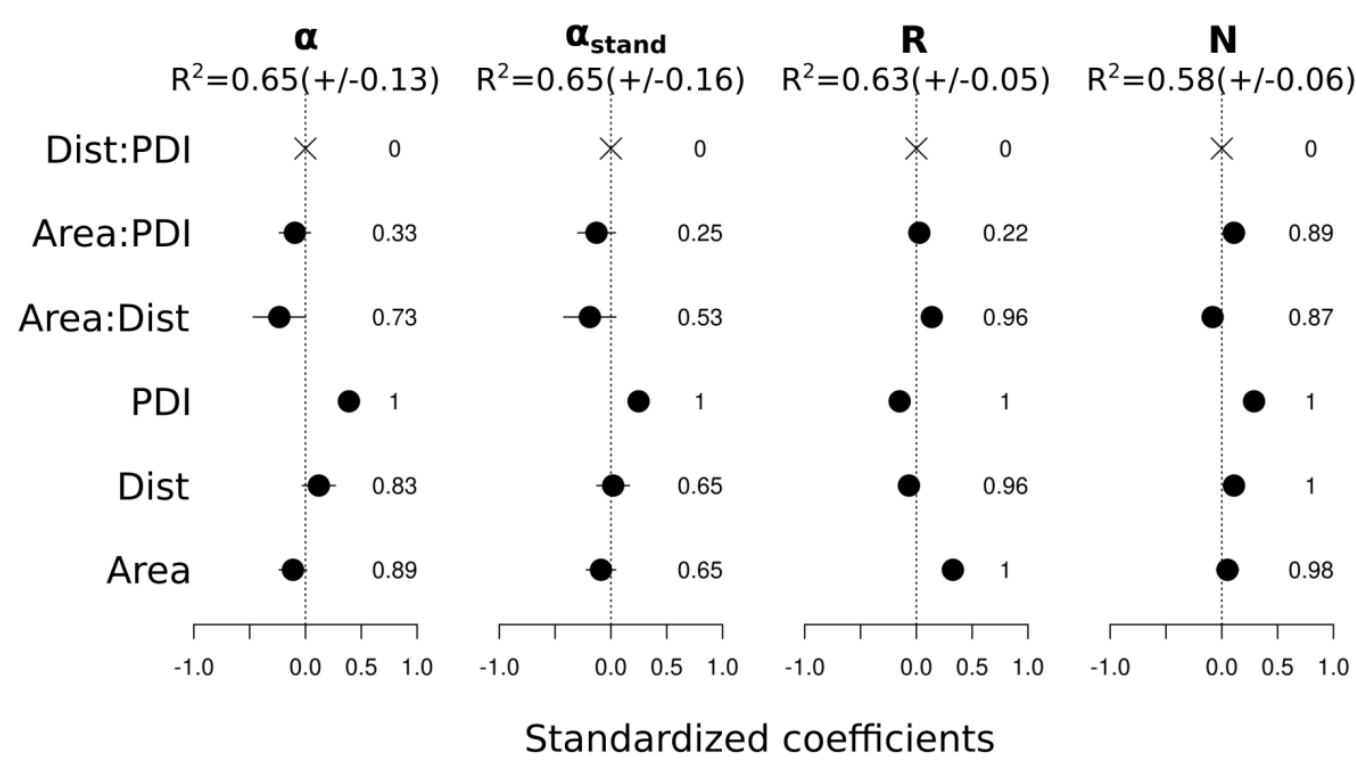

'This article is protected by copyright. All rights reserved.' 
Figure 5 Linear regressions illustrating the relationships between the cyclone power dissipation index (PDI), island area (Area, log-transformed), island isolation (Dist., logtransformed), and the shape parameter ( $\alpha$ ) of SADs, the standardized shape parameter $\left(\alpha_{\text {stand }}\right)$, the number of trees, and the number of species. Points represent the average value per island, bars the minimal and maximal values. Grey, solid trend lines represent the fits of 500 iterations of generalized linear models where a single plot was randomly selected for islands with multiple plots. Solid black trend lines represent the average fits with averaged $\mathrm{R}^{2}$ and $P$ values (distributions of $\mathrm{R}^{2}$ and $P$ values are available in Supporting Material S2). Dotted black trend lines represent the 95\% confident intervals around the average trend lines. Trend lines where only showed when at least one iteration resulted in a significant relationship $(P<0.05)$. 

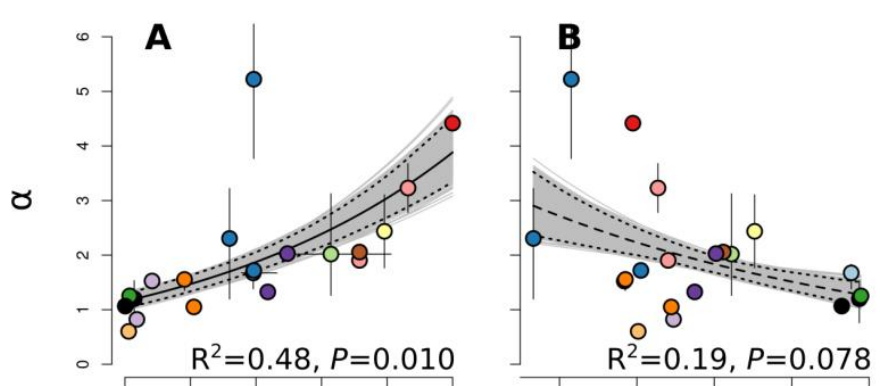

C

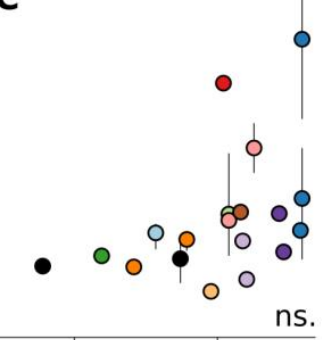

Archipelagos

O Andaman

O D'Entrecasteaux

O Fiji

Greater Sunda

O Hainan

O Madagascar

O Mascarene

O New Caledonia

New Guinea

O Philippine

Samoa

Ô Solomon

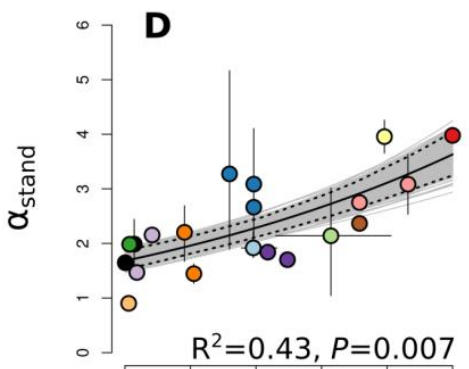

$\mathbf{E}$

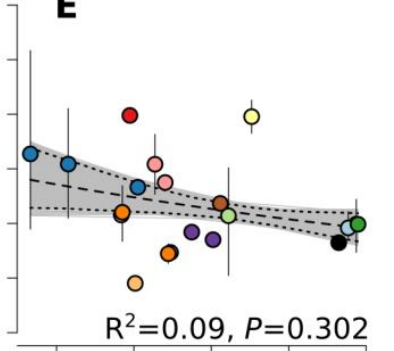

$\mathbf{F}$

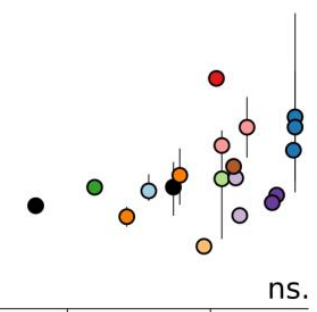

H

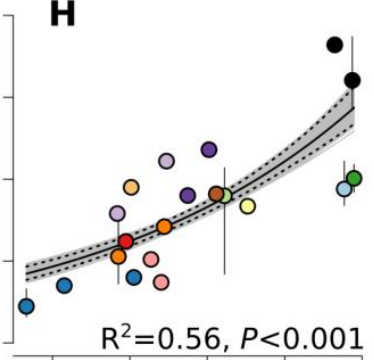

I.
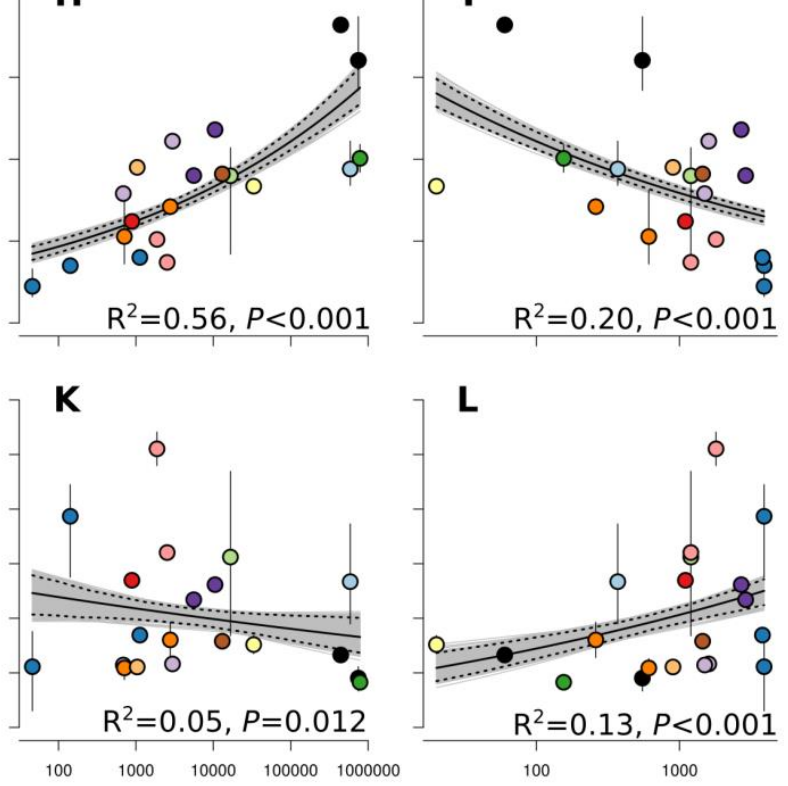

Area $\left(\mathrm{km}^{2}\right)$
$\mathbf{L}$

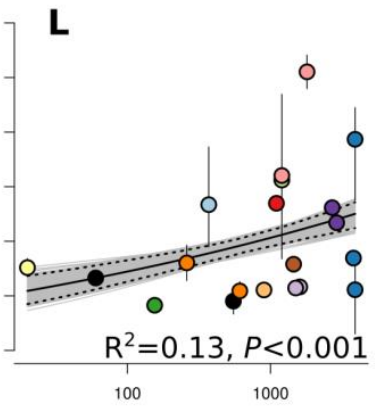

Dist. (km) 
Figure 6 Partitioning of the variance in the shape parameter $(\alpha)$ of SADs and the standardized shape parameter $\left(\alpha_{\text {stand }}\right)$. Bold values shown in the diagrams are the average proportion of variance (+/- one standard deviation) explained by the cyclone power dissipation index (PDI, A and C) or island biogeography (Area x Dist, B and D), the number of trees $(\mathrm{N})$, the number of species $(\mathrm{R})$, and the interactions between these factors (500 iterations).
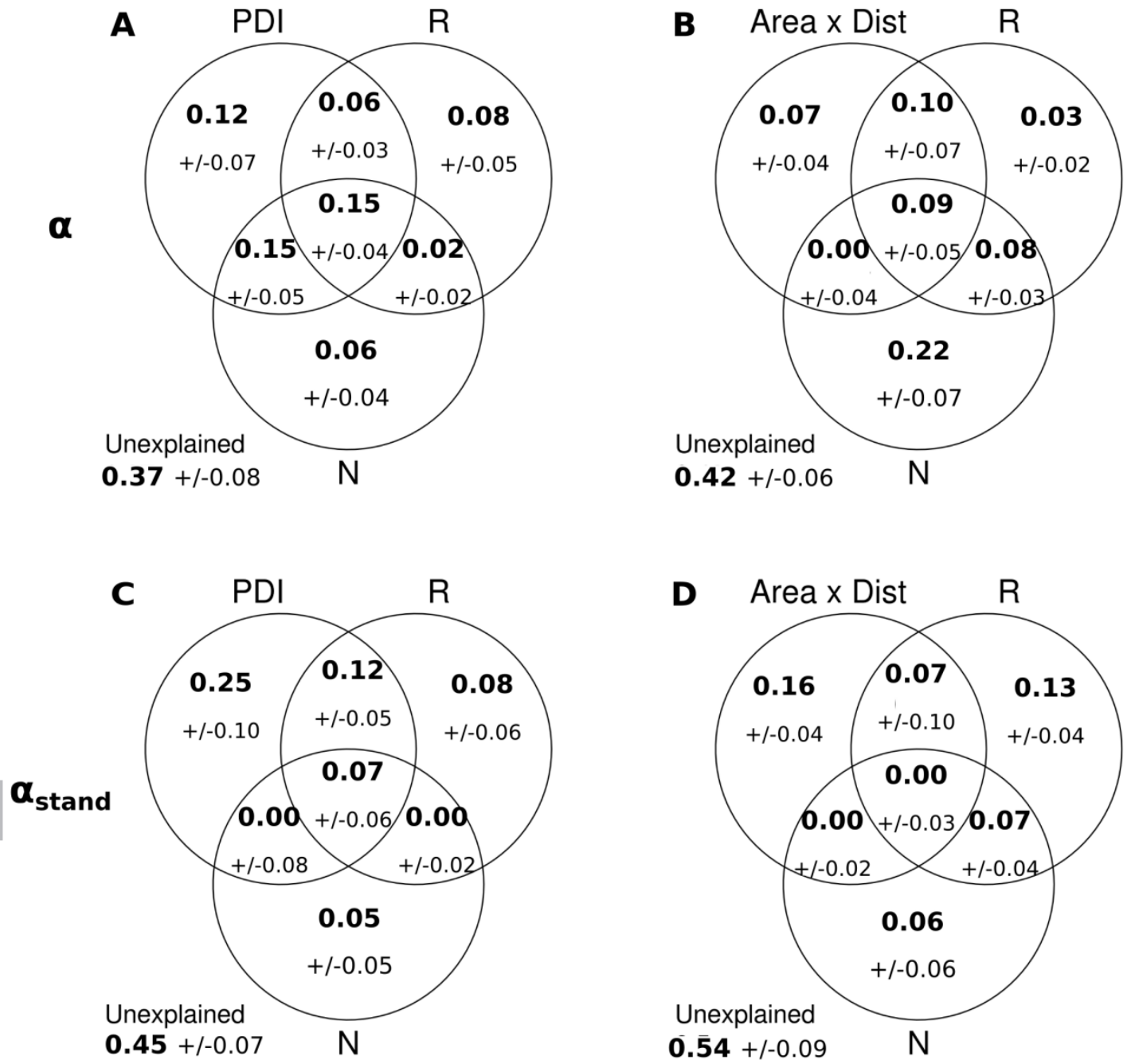


\section{Table Legends}

Table 1 Data set description, providing the number of plots per island and archipelago, and the sources of the plot data used.

\begin{tabular}{|c|c|c|c|}
\hline Archipelago & Island & lo. & Data sources \\
\hline \multirow[t]{2}{*}{ Andaman } & Little Andaman & 4 & Rasingam \& Parthasarathy (2009) \\
\hline & Middle Andaman & 2 & Rajkumar \& Parthasarathy (2008) \\
\hline D'Entrecasteaux & Normanby & 1 & Keppel, Buckley \& Possingham (2010) \\
\hline \multirow[t]{2}{*}{ Fiji } & Vanua Levu & 1 & Keppel, Buckley \& Possingham (2010) \\
\hline & Viti Levu & 1 & Keppel, Buckley \& Possingham (2010) \\
\hline \multirow[t]{2}{*}{ Greater Sunda } & Borneo & 3 & $\begin{array}{l}\text { Aiba \& Kitayama (1999); Small, Martin, } \\
\text { Kitching \& Wong (2004) }\end{array}$ \\
\hline & Sumatra & 1 & $\begin{array}{l}\text { Kartawinata, Samsoedin, Heriyanto \& Afriastini } \\
\text { (2004) }\end{array}$ \\
\hline Hainan & Hainan & 2 & Lu et al. (2014) \\
\hline Madagascar & Madagascar & 3 & Birkinshaw, Reza \& Ratovoson (unpublished) \\
\hline \multirow[t]{2}{*}{ Mascarene } & La Reunion & 1 & Strasberg (1996) \\
\hline & Mauritius & 2 & Florens \& Baider (unpublished) \\
\hline New Caledonia & Grande Terre & 13 & Ibanez, Blanchard et al. (2018) \\
\hline New Guinea & New Guinea & 2 & $\begin{array}{l}\text { Laidlaw, Kitching, Goodall, Small \& Stork } \\
\text { (2007) }\end{array}$ \\
\hline
\end{tabular}


Philippine

Samoa

Ta'u

Tutuila

Upolu

Choiseul

Kolombangara

Vanuatu

Erromango

Solomon

1 Hamann, Barbon, Curio \& Madulid (1999)

6 Webb, Van de Bult, Chutipong \& Kabir (2006)

$4 \quad$ Webb \& Fa'aumu (1999)

$1 \quad$ Keppel, Buckley \& Possingham (2010)

$1 \quad$ Keppel, Buckley \& Possingham (2010)

$1 \quad$ Keppel, Buckley \& Possingham (2010)

$1 \quad$ Keppel, Buckley \& Possingham (2010) 